\title{
Movimentos Migratórios e Cidadania: a Onipresença das Fronteiras
}

\author{
Vera Lúcia Follain de Figueiredo \\ Doutora em Letras, professora Adjunta \\ do Departamento de Comunicação \\ Social da PUC-Rio e pesquisadora \\ do CNPq. É autora, dentre outros \\ trabalhos, dos livros: Narrativas \\ migrantes: literatura, roteiro e \\ cinema (PUC/7 letras), Os crimes \\ do texto: Rubem Fonseca e a ficção \\ contemporânea (UFMG) e Da profecia \\ ao labirinto: imagens da história \\ na ficção latino-americana (Imago/ \\ UERJ). Organizou os livros Mídia e \\ Educação (Gryphus) e Comunicação, \\ representação e práticas sociais, este \\ último juntamente com Renato Cordeiro \\ Gomes e Miguel Pereira (PUC/ Idéias e \\ Letras). Email: verafollain@gmail.com
}

Resumo: $O$ termo cosmopolitismo que, até bem pouco tempo, em decorrência das novas configurações da sociedade contemporânea, perdera espaço para noções como a de globalização, voltou ao primeiro plano, sendo retomado em diversos textos teóricos recentes. $O$ artigo discute a ressignificação do conceito, bem como a pertinência de expressões como "cosmopolitismo do pobre" e "cosmopolitismo subalterno" quando se trata de descrever os movimentos migratórios deste início do século XXI.

Palavras-chave: Cosmopolitismo; Globalização; Cosmopolitismo dos pobres; Imigração.

\section{Title: Migratory Movements and Citzenship: the Omnipresence of the Frontiers}

Abstract: The idea of cosmopolitanism, which had lost ground for notions such as globalization consequent upon contemporary society new configurations, recovered prominence, having reappeared in several recent theoretical texts. The article discusses the new meaning of the concept as well as the relevance of expressions such as "cosmopolitanism of the poor" and "subaltern cosmopolitanism" when it comes to describing the migratory movements of the early twenty-first century.

Keywords: Cosmopolitanism; Globalization; Subaltern Cosmopolitanism; Immigration.

\begin{abstract}
Os participantes da Comuna de 1871 pensavam que tinham direito a recuperar "sua" Paris das mãos da burguesia e dos lacaios imperiais. Os monárquicos que os mataram, por sua parte, pensavam que tinham direito a recuperar a cidade em nome de Deus e da propriedade privada. Não estavam todos, acaso, exercendo seu direito à cidade? "A direitos iguais" -constatou celebremente Marx - "a força decide." É a isto que se reduz o direito à cidade?.
\end{abstract}

David Harvey

Para nós latino-americanos, "cosmopolita" é um vocábulo sobrecarregado de implicações simbólicas. Remete, de imediato, para a dicotomia particular/ universal, cujos termos foram, em diferentes momentos, considerados extremos que se excluem, na mesma lógica disjuntiva que levou Sarmiento a cunhar a famosa polarização: civilização ou barbárie. Com a identificação entre "civilização", "cultura ocidental" e "modernização" caracterizou-se, muitas vezes, o particular como aquilo que resistia ao processo ocidentalizante, situando-o do 
lado do provincianismo que, nesta perspectiva, tornava-se sinônimo de barbárie. No Brasil, entretanto, tal concepção extremada nem sempre prevaleceu. Alencar buscou, em Moacir, filho de Iracema e Martim, a conciliação entre o elemento indígena e o europeu. Euclides da Cunha acabou por relativizar as categorias rígidas do pensamento de base cientificista para não ter que condenar o sertanejo à exclusão e Oswald de Andrade concebeu fórmulas inclusivas como "a floresta e a escola", o "misto de dorme nenê que o bicho vem pegá e de equações", como vemos no Manifesto da Poesia Pau-Brasil.

Já no ensaio "O escritor argentino e a tradição", de 1953, Jorge Luis Borges buscava ultrapassar os dualismos que balizavam a cultura argentina - entre gauchos ou portenhos, cultura autóctone ou cultura europeia - negando-se a escolher entre dois extremos (como Sarmiento propusera) assim também como rejeitando o caminho da síntese entre opostos (como indicara Oswald). Para Borges era necessário romper com as amarras do que considerava um pseudoproblema, um tema retórico, apto para desenvolvimentos patéticos. Evocando uma tradição mais ampla - a tradição ocidental - procurava mostrar que as fronteiras da literatura não se confundiam com as fronteiras nacionais. Denunciava o culto da cor local como invenção recente, apontando o seu caráter forasteiro. Para ele, ironicamente, a ideia de que os escritores devem buscar temas de seus países deveria ser rechaçada pelos nacionalistas, visto que fora inventada na Europa.

Segundo Borges, existiria uma literatura ocidental com seus centros e suas margens: é nela que estaríamos incluídos. Antecipando críticas que viriam a se tornar correntes desde as duas últimas décadas do século passado, rejeita a dicotomia local/universal, porque quer se situar além das compartimentalizações consagradas pela visão moderna, nas quais essa oposição se enquadra. Assinala o caráter histórico e circunstancial das categorias classificatórias estabelecidas pela modernidade, propondo uma outra maneira de olhar a cultura, que recusaria tanto o localismo infenso a influências estrangeiras quanto o caráter programático do projeto modernizador. Busca, desse modo, superar as polarizações que marcaram profundamente a política e toda a produção cultural argentina. Ser argentino, para o escritor, é uma realidade que não se contrapõe à virtualidade de pertencer à tradição universal. Com isso, descarta, como meras proposições retóricas, a dicotomia civilização/barbárie e todas as demais oposições que compõem o mesmo paradigma, como entre cultura local/cultura ocidental.

Muitas décadas depois da publicação do texto "O escritor argentino e a tradição", a tensão entre particularismo e universalismo continua pontuando debates sobre os rumos a serem tomados pela alta cultura latino-americana, chegando até o século XXI, como se vê, por exemplo, na conferencia intitulada Itinerários extraterritoriais, proferida pelo escritor mexicano Juan Villoro, em 2001, na cidade de Munique. Villoro, cuja residência se divide entre Espanha e México, aproveitou aquela oportunidade para assinalar que a América Latina costuma ser vista pela Europa e pelos Estados Unidos como uma reserva fascinante pelo seu atraso, pelo que mantém de um mundo primitivo, agitado, experimental, um laboratório de excessos. Daí decorreria, segundo ele, que as formas de representação desse contexto pareçam mais autênticas quando perpassadas "pela magia ou pela intuição, por procedimentos quase rituais em que o artista atua como um xamã temerário" (2014: 147). A América Latina, aos olhos dos países centrais, não estaria tão distante da artificialidade dos parques temáticos da Disney World. Diz então:

Se fossem combinados os esforços do arquiteto Frank Gehry, dos técnicos da Disney World e de um colegiado de antropólogos, seria possível construir um parque temático que resumisse os tópicos "latino-americanos", com o efeito seguro de que a realidade ficasse de fora, um horizonte protegido, de uma pureza indefinida. (2014: 148) 
Villoro levanta a bandeira da extraterritorialidade da literatura para defender, com inflexão indignada, a qualidade do trabalho dos escritores latinoamericanos: estes, como seus pares oriundos das culturas hegemônicas, também enfrentariam desafios técnicos, isto é, não seriam apenas criaturas hipersensíveis que tiram partido da realidade pitoresca que os cerca. Tal defesa apaixonada do cosmopolitismo dos escritores latino-americanos atualiza o velho debate em torno da dicotomia entre particularismo e universalismo, que, como vimos, Jorge Luis Borges, nos idos dos anos de 1950, já considerava um pseudoproblema e que, a dizer pelo tão propalado enfraquecimento dos discursos identitários no mundo globalizado, já deveria ter se tornado mesmo uma questão obsoleta.

O autor mexicano, no entanto, briga em duas frentes: uma situada no passado e outra no presente. No passado, o alvo da crítica, partilhado com outros escritores interessados em abrir espaço no campo literário para a sua própria geração, é a literatura do realismo maravilhoso e, mais precisamente, Gabriel García Márquez. Parece, então, levar ao pé da letra a afirmativa do autor colombiano de que "os escritores da América Latina e do Caribe têm de reconhecer, com a mão no coração, que a realidade escreve melhor" (2006: 203) - afirmativa que, entretanto, não se enquadraria na oposição forma $x$ conteúdo, que baliza as queixas de Villoro. Tal argumento de Gabriel García Márquez insere-se numa visão diferente da cultura, que, contrapondo-se à razão burguesa separada do imaginário coletivo, diluindo a rígida divisão entre erudito e popular, aproxima o escritor do cronista oral, do contador de histórias. $O$ próprio estatuto da ficção é alterado: antes de ser uma arte, ou antes que as artes dela se apoderem, a ficção seria um regime de percepção.

No presente, o alvo da crítica de Villoro é o que chama de "as novas modas" do pós-colonialismo e do multiculturalismo. O primeiro teria criado, no afã de recuperar culturas menosprezadas, um folclore purista, que descartava as combinações como mostras espúrias: na academia norte-americana proliferariam cursos nos quais os romances latino-americanos seriam meros veículos para entender o caudilhismo, o machismo e outras essências latino-americanas (2014: 151). O segundo anestesiaria a avaliação dos costumes alheios, caindo numa indiscriminada aceitação do desconhecido, ou mesmo do aberrante, como algo simplesmente distinto (2014: 148).

Em outra conferência, realizada em 2013, Villoro recupera desde o título - "De Quetzalcóatl a Pepsicóatl" - o amargo jogo de palavras criado por Carlos Fuentes no livro Tiempos mexicanos, de 1971. Nesta obra, Fuentes comenta o uso simbólico que se deu à garrafa de Pepsi-Cola em San Juan Chamula, explicando que em aldeias remotas, quem controlava os refrigerantes tinha uma fonte de poder. Assim, não era casual que na igreja San Juan Chamula, oficiantes bebessem aguardente em uma garrafa de Pepsi, identificada como talismã de mando. A partir desse fato, Fuentes afirma que de Quetzalcóatl a Pepsicóatl, "o tempo mítico do indígena se sobrepõe ao tempo do calendário ocidental, tempo do progresso, tempo linear" (1972: 46). Villoro, então, acrescenta que os refrigerantes dominam a dieta, a economia e as consciências e que, em consequência, os mexicanos têm o índice mais alto de obesidade infantil, triste recorde mundial que compartilham com outro, o de maior exposição a anúncios de junk food, de comida rápida e de baixa qualidade, na televisão: "a enfermidade se promove como uma guloseima", diz ele.

Tais questões, tão debatidas nos países latino-americanos, decorrentes das misturas de modos de vida e de imaginários, assim como dos "desvios" provocados pela ação do mercado, ganham cada vez mais espaço no contexto contemporâneo da globalização. Daí a atenção que a noção de cosmopolitismo tem merecido por parte de vários pesquisadores do campo das chamadas Ciências Sociais, começando por Boaventura de Sousa Santos a quem se deve a expressão "cosmopolitismo subalterno". Para Boaventura, o cosmopolitismo tem sido privilégio de poucos, por isso torna-se necessário revisitar o conceito, propor um 
uso alternativo, voltado para os grupos cujas aspirações são negadas ou tornadas invisíveis pelo uso hegemônico do conceito. Da mesma forma que a globalização neoliberal não reconhece quaisquer formas alternativas de globalização, também o cosmopolitismo sem adjetivos negaria a sua própria especificidade. O cosmopolitismo subalterno de oposição seria, então, uma forma cultural e política de globalização contra-hegemônica: consistiria no "nome dos projetos emancipatórios cujas reivindicações e critérios de inclusão social vão além dos horizontes do capitalismo global" (2007). O cosmopolitismo subalterno estaria a serviço de todo aquele que foi vítima de intolerância e discriminação, de todo aquele a quem foi negada a cidadania, ou seja, dos socialmente excluídos.

Sem deixar de levar em conta a importância de algumas proposições que envolvem mudanças discursivas relativas ao cosmopolitismo, no âmbito deste artigo, optamos por formular perguntas tendo como horizonte a concepção moderna de cosmopolitismo, que, como destacou Renato Cordeiro Gomes, tem sua base no lluminismo, pressupondo uma ética pela qual todos os seres humanos são tratados como se fossem cidadãos do cosmos, no sentido de universo (2014: 3): interessa-nos o caráter inclusivo dessa formulação conceitual. É a partir dele que indagamos, por exemplo, que circunstâncias teriam gerado o neoindigenismo dos chicanos. Como falar de cosmopolitismo quando se busca no resgate do maior número possível de elementos culturais do império perdido, os pilares ideológicos para reconstruir, em terra alheia, as formas da mexicanidade? Tal movimento de ancoragem nos referenciais da cultura de origem apontaria para a construção de uma identidade chicana que não é nem mexicana nem norte-americana? Por outro lado, as situações limite vividas pelos imigrantes, tais como as retratadas por Ken Loach, em Pão e Rosas (França, Reino Unido, Espanha, Alemanha e Suíça, 2000) reforçariam os laços com a nacionalidade? O filme tematiza a violência a que se submetem aqueles que, não tendo obtido visto de entrada no país, pretendem cruzar a fronteira entre México e Estados Unidos, bem como os problemas enfrentados pelos trabalhadores imigrantes, vindos de diferentes regiões do continente americano. Na cena em que são fichados na delegacia, três trabalhadores substituem seus verdadeiros nomes pelos de Emiliano Zapata, Pancho Villa e Augusto Sandino: ou seja, diante da repressão, do confronto com a ordem policial do país de entrada e da incerteza quanto ao que ia lhes acontecer, os imigrantes recuperam os nomes de seus heróis nacionais, o que traz à tona as desconfianças geradas pelas múltiplas lealdades daqueles que vivem em terra estrangeira.

Aliás, ao tentar explicar por que a década de 1990, período do auge da globalização, foi também um período de violência etnocida em larga escala, o antropólogo indiano Arjun Appadurai, crítico ferrenho do Estado-nação moderno, aponta a incerteza como uma das causas principais dessa violência, indagando:

(...) por que uma década dominada pela aprovação global dos mercados abertos e da livre circulação do capital financeiro, por ideias liberais a respeito das regras constitucionais e do bom governo e por uma ativa expansão dos direitos humanos produziu, por uma parte, uma pletora de casos de limpeza étnica e, por outra, formas extremas de violência política contra populações civis? (2007: 15)

Ao responder tal pergunta é obrigado a reconhecer que a violência étnica não é apanágio exclusivo do Estado-nação, admitindo que, para compreendê-la, tornase necessário atribuir-lhe uma outra causa, isto é, o lugar que a incerteza ocupa na vida da sociedade. As formas dessa incerteza seriam várias:

Esta classe de incerteza está intimamente relacionada com o fato de que os grupos étnicos de hoje se contarem aos milhares e seus movimentos, mesclas, estilos culturais e representação nos meios de comunicação criam dúvidas 
profundas acerca de quem exatamente se acha dentro do "nós" e quem dentro do "eles". (...) No contexto de uma emigração rápida ou movimento de refugiados, quantos deles estão agora entre nós? (2007: 18)

A globalização, para Appadurai, acabaria por exacerbar as inseguranças, produzindo incentivos novos para a purificação cultural à medida que mais nações perdem a ilusão da soberania econômica nacional e do bem-estar.

Como se vê, se por um ângulo, os princípios constitutivos do Estado-Nação estão sendo minados pela fonte multirracial e pela economia transnacional, como destaca Silviano Santiago (2004: 58), por outro, várias tendências situam-se na contramão deste enfraquecimento, o que se confirma, por exemplo, pelo fato de o mundo assistir, depois de 1989, a uma profusão de aparecimentos de novos Estados nacionais. Embora não se possa negar que a natureza de várias crises contemporâneas exceda os limites da nação e atravesse as identidades culturais e linguísticas é preciso lembrar que, hoje, fazem parte das Nações Unidas muito mais nações do que antes da queda do muro de Berlim, o que torna a questão ainda mais complexa.

Nesse contexto, o significado que se atribuía a "cosmopolitismo", há não muitas décadas atrás, tendeu a se modificar, inclusive em decorrência da maior facilidade de locomoção proporcionada pelo avanço tecnológico no campo dos meios de transporte. No passado, para nós, latino-americanos, cosmopolitas eram os membros das elites abastadas que detinham o privilégio de circular pelas metrópoles europeias: além do poder aquisitivo suficiente para arcar com as despesas da viagem entre continentes distantes, tais indivíduos caracterizavamse por ter recebido uma educação de caráter universalizante, que Ihes permitia algum domínio das línguas estrangeiras, contribuindo também para a diluição de marcas identitárias indesejáveis quando se pretende contornar o sentimento de inferioridade diante dos colonizadores. Ainda que, na visão geral, este cosmopolitismo dos ricos fosse marcado positivamente, quase como um valor em si, não se constituía necessariamente numa garantia contra os preconceitos: associou-se, muitas vezes, à confirmação de estereótipos, ao colonialismo, fortalecendo o vínculo subserviente com a cultura do país dominante no cenário internacional, como observou Gilberto Velho (2010).

Assim, se a ideia de cosmopolitismo nos enreda numa série de problematizações decorrentes de nossa condição de países periféricos, a expressão "cosmopolitismo do pobre", adotada por Silviano Santiago, provoca um certo estranhamento, se atribuímos ao termo cosmopolita o significado de cidadão do mundo. Tomo, então, como referência, três cenas cinematográficas. A primeira retirada do filme Caché (França/Áustria/Alemanha/Itália, 2005), de Michael Haneke: o personagem, um intelectual francês estressado, ofende um negro que involuntariamente quase o atropela com a bicicleta: este, por sua vez, não se intimida e, ao enfrentar o primeiro, deixa aflorar também todo o seu ressentimento. A segunda cena é do filme brasileiro Terra estrangeira, de Walter Salles e Daniela Thomas (Brasil/Portugal, 1995): imigrantes angolanos, vivendo fechados entre si, em gueto, interpelam o companheiro que introduz o personagem brasileiro no ambiente em que moram, preocupados com a própria segurança. A terceira cena está no filme Entre muros, de Laurent Cantet (França, 2008), baseado no livro homônimo, de François Bégaudeau, e exibido no Brasil com o título de Entre os muros da escola: a mãe de um dos alunos de uma escola francesa, onde estudam adolescentes nascidos no país e filhos de imigrantes de várias procedências, comparece à escola onde deverá ser informada sobre a conduta inadequada do filho, mas não entende o idioma francês.

As três cenas colocam em a pauta barreiras culturais e linguísticas, bem como as tensões históricas constituídas pelo processo da colonização. Como chamar de cosmopolitas os imigrantes pobres que não dominam a língua do país para onde se deslocaram, retratados no filme Entre muros? Como considerar cidadãos do mundo os angolanos de Terra Estrangeira, ou ainda o negro argelino discriminado 
${ }^{1}$ Dentre as ressemantizações do termo cosmopolitismo podemos citar: cosmopolitismo patriótico (APPIAH, 1998); cosmopolitismo vernáculo (BHABHA, 1996); cosmopolitismo enraizado (COHEN, 1992); cosmopolitismo das classes trabalhadoras (WREBNER, 1999). nas ruas de Paris? A situação daqueles que entram pela porta dos fundos num país estrangeiro, que vivem na clandestinidade, remete para o avesso do que até bem pouco tempo chamávamos de cosmopolitismo e nem sempre é contemplada pelas novas teorias que ressemantizam o termo ${ }^{1}$.

Ulrich Beck, por exemplo, no livro La mirada cosmopolita o la guerra es la paz (2006), propõe que o termo substitua o de globalização ou de mundialização, pois estes últimos, para ele, ainda preservariam as polaridades interior/exterior, nacional/ internacional, que o cosmopolitismo deixaria para trás. O olhar cosmopolita possuiria o sentido do mundo: é lúcido e busca estabelecer um diálogo com as numerosas ambivalências que se dão na época atual. Não sendo um novo universalismo, surgiria dos fatos, pois a realidade mesma teria se tornado cosmopolita. A União Europeia é a referência do sociólogo alemão, que a considera uma ilustração histórica da sua teoria, um exemplo de soberania ampliada.

O cosmopolitismo redefinido por Ulrich Beck, pairando acima dos problemas concretos, passa ao largo do fato de que a mobilidade dos pobres está frequentemente ameaçada pelos procedimentos de controle das fronteiras através dos quais as ideias de migração e de ilegalidade tendem a se misturar. No mundo global, o aumento da imigração é visto, por grande parte da população nascida nos países de entrada, como ameaça à segurança e à estabilidade. Por outro lado, o próprio liberalismo pede a abertura das fronteiras para o intercambio de bens e dinheiro. A fronteira, forte símbolo da soberania nacional, é abalada também por redes transnacionais de negócios que atravessam os Estados, desafiando os poderes internos tanto quanto os desafiam os que transgridem as fronteiras físicas, buscando trabalho, oportunidades de conquista de uma vida melhor.

Por tudo isso, as fronteiras despertam, cada vez mais, a atenção de várias instituições da sociedade e atraem diversos tipos de indivíduos, gerando, inclusive, uma economia da clandestinidade, tanto mais forte quanto mais aumentam as barreiras à imigração - quanto mais se fecham, mais lucro, por exemplo, para os traficantes de seres humanos e de passaportes, assim como para os que engrossam a demanda de mão de obra barata das sociedades avançadas, empregando trabalhadores sem documentos e, portanto, sem nenhum direito. Tensões que o fragmento de número 055, intitulado, "Fronteiras", do livro Passaporte, de Fernando Bonassi, expressa de maneira contundente:

Cercas reforçadas \& enterradas com alicerces de concreto para baixo\& além de túneis possíveis, dividindo um deserto em dois desertos. Os Estados Nacionais palpáveis como cacos de vidro. Guardas sérios, quase soldados, mais que autorizados, prestes a... Um movimento em falso e... Muit'a'tensão. Mochilas, poder de fogo, remela \& mau-hálito. Passaportes esquecidos, passaportes aquecidos, suados, naftalínicos - passados de mão em mão como coisas bentas ou boas biscas. Animais humanos de olhos arregalados, preparando botes, encoxando guichês. (Dresden/Teplice - Alemanha/República Checa - 1998)

Como observamos em obra anterior (2010:222), o autor nos dá o retrato instantâneo da violência de um sistema que se alimenta da mobilidade das mercadorias, do capital e das imagens, mas bloqueia o deslocamento de um número significativo de pessoas. Para a elite cosmopolita é possível viajar escolhendo livremente o destino, segundo seus desejos. Para os emigrantes em busca de meios de subsistência nos países hegemônicos, as fronteiras tendem a ser cada vez mais intransponíveis. A situação de miserabilidade força o imigrante não só a vender, a qualquer preço, sua força de trabalho, conforme se vê no já citado filme Pão e Rosas, como a disponibilizar seu corpo como suporte de mercadorias proibidas: o corpo-valise, esvaziado de seu caráter de totalidade orgânica, serve de recipiente e canal por onde a mercadoria proibida circula, desafiando o corpo da lei. 
Os muros visíveis e invisíveis a serem transpostos, pelo migrante pobre, são muitos. Há as fronteiras simbólicas, os novos limites que se constroem dentro dos Estados a partir de filiações étnicas, condições raciais, financeiras ou religiosas:

Desde os anos 90, a clandestinidade faz parte do projeto migratório dos viajantes que a consideram uma etapa obrigatória. (...) Em poucas palavras, foi a aparição de um certo tipo de fronteira que construiu um olhar particular sobre os estrangeiros percebidos como criminosos e confundidos com o inimigo interior e exterior. (WENDEN, 2013: 88/89)

As fronteiras urbanas, que visam delimitar o território dos excluídos das benesses do capitalismo de consumo, são a face doméstica das fronteiras internacionais, cada vez mais fechadas aos egressos dos países periféricos, com o acirramento da segregação espacial. No caso da nação de origem, o movimento migratório aponta para o afrouxamento dos laços internos, para a descrença no ideal de construção de um projeto coletivo, que implicaria, em princípio, o compromisso de todos. A nacionalidade como sinônimo de restrição espacial é, no entanto, a contrapartida da extraterritorialidade do poder financeiro, como observou Zygmunt Bauman:

Surge uma nova assimetria entre a natureza extraterritorial do poder e a contínua territorialidade da "vida como um todo" - assimetria que o poder agora desarraigado, capaz de se mudar de repente sem aviso, é livre para explorar e abandonar às consequências dessa exploração. Livrar-se da responsabilidade pelas consequências é o ganho mais cobiçado e ansiado que a nova mobilidade propicia ao capital sem amarras locais, que flutua livremente. (1999: 16)

É para essa assimetria - a extraterritorialidade do poder e a territorialidade da vida do homem comum - que uma determinada vertente da ficção da última década vem apontando, ao tematizar a consolidação de uma cultura do dinheiro, a desvalorização do trabalho produtivo e o descompromisso com um comportamento ético na sociedade contemporânea: os referenciais de valor parecem flutuar livremente, como os fluxos do capital sem domicílio, que se situa muito além dos controles dos governos nacionais. Tal volatilidade constitui o tema O Capital, de Costa Gravas (França, 2012), baseado no romance de mesmo nome, do francês Stéphane Osmont. Neste filme, as notícias plantadas na mídia pelos homens do mundo financeiro seguem os planos arquitetados pelos especuladores, com consequências desastrosas para a vida econômica de diferentes países e dos indivíduos que neles trabalham.

O verdadeiro cosmopolitismo seria o do capital, para o qual não existem fronteiras. Grandes empresas instalam-se simultaneamente em vários países, determinam o que cada um deles deve produzir e impõem uma divisão internacional do trabalho: é principalmente em função desta divisão internacional do trabalho, insuficientemente ressaltada na maioria dos textos que abordam os fluxos migratórios atuais, que se constitui o que vem se convencionando chamar de cosmopolitismo do pobre, embora não se deva esquecer que não é de hoje que os pobres se deslocam em busca de maiores oportunidades de subsistência. De qualquer forma, uma das mudanças mais significativas é o fato de ter se tornado impossível, no mundo contemporâneo, estabelecer uma linha divisória simples entre ricos que viajam e pobres forçados a permanecer em seus lugares. Ironicamente, muitas reivindicações localistas de autonomia têm sido iniciativa dos ricos, enquanto os pobres levantam bandeiras universalistas.

Voltando aos filmes cujas cenas destacamos, pode-se afirmar que têm o mérito de lembrar uma outra conexão - a que existe entre migração e colonização - que também tende, hoje, a ser elipsada, embora os fluxos migratórios frequentemente repitam, com a direção invertida, as rotas históricas da colonização. Em Terra 
estrangeira, o jovem brasileiro sem perspectiva, estimulado pelo desejo da mãe que não resistiu ao confisco da poupança realizado pelo governo Collor, propõe-se a refazer, no sentido inverso, o movimento dos conquistadores da América Latina, adotando, como os antepassados nos séculos XV e XVI, a viagem como solução para os problemas. A emigração para a Europa assume, assim, o caráter de volta sobre os próprios passos, de busca de uma origem mais remota onde tudo teria começado - esforço que resulta estéril. Os imigrantes do filme não se tornam cosmopolitas: ao contrário, sentem-se estrangeiros em qualquer parte da terra, pois a nação, que não Ihes serve mais de referencial, continua constituindo, no entanto, um referencial para os estereótipos discriminadores que os marginalizam no exterior. Brasileiros e angolanos, no filme Terra estrangeira, não têm a mesma sorte dos portugueses colonialistas que se deslocaram para países africanos e para o Brasil. São condenados a viver à margem da cidadania, no circuito da ilegalidade.

Entre muros, vencedor de vários prêmios, dentre eles a Palma de Ouro, em Cannes, discute, para além das dificuldades específicas dos imigrantes no campo da educação escolar, problemas suscitados pela diferença cultural. Trata-se de discutir os muros que não foram derrubados, isto é, todas as espécies de barreiras que se erguem entre "o mesmo" e os "outros", dentre elas, a divisão entre os que sabem e os que não sabem pautada pela oposição entre universal e particular - divisão que os alunos, filhos de imigrantes, de Entre muros, questionam, nos embates em sala de aula, ao colocar em dúvida a validade do saber que lhes é transmitido pelo professor francês.

Já o filme Caché, como o próprio título sinaliza, remete para o que as aparências encobrem, para o recalque das lembranças no plano individual e para o apagamento da memória coletiva pelos discursos oficiais. Daí que a origem do problema que será vivido pelo personagem principal quando adulto, já no século XXI, está no passado, na infância, e mais precisamente no ano de 1961, quando ocorreu um episódio cuja gravidade a história oficial francesa procurou negar: o massacre, levado a cabo pela polícia francesa, de centenas de argelinos que participavam de uma manifestação pacífica em Paris, no dia 17 de outubro, num momento em que os dois países já negociavam o fim da guerra pela independência da Argélia.

Em Caché, os pais do personagem Majid, que eram empregados na casa da família de Georges Laurent, morreram nesta manifestação de 1961. Os patrões resolvem, então, adotar o menino que ficou órfão, o que não se realiza em função de uma intriga criada pelo filho deles, de seis anos de idade. Georges, que não quer dividir seu espaço com Majid, o acusa de ter matado um galo para assustá-lo, ameaçando-o com a faca suja de sangue. O filho dos empregados argelinos é, então, enviado para um orfanato. Esse passado surge fragmentariamente na narrativa fílmica à medida que Georges, já adulto, tendo se tornado famoso como apresentador de um programa de televisão sobre literatura passa a receber mensagens anônimas que lhe roubam a tranquilidade. A vida normal de sua família será abalada pelo recebimento de pacotes com fitas de vídeo e desenhos, sem qualquer identificação do remetente, além de telefonemas de um estranho que procura por Georges. Nas fitas pode se ver a fachada da casa em que moram, o movimento de entra e sai da família e de poucos transeuntes no pequeno trecho da rua residencial.

Essas imagens silenciosas, tomadas de um ponto determinado da rua, por alguém desconhecido, serão suficientes para dar início a um processo em que, pouco a pouco, a paz da família se esvai. A tranquilidade do espectador também é perturbada e logo na primeira cena: o filme se inicia com um plano fixo da fachada da casa, mas, minutos depois, a imagem é rebobinada e somos remetidos para o interior da casa onde George e sua mulher, Anne, assistem ao vídeo. O espectador se dá conta, então, de que seu olhar não contemplava a ação presentificada, mas a reprodução em vídeo de uma imagem. Daí por diante, toda tomada externa em plano fixo Ihe causará apreensão. $O$ deslizamento entre imagens captadas por câmeras que 
cumprem funções diversas na economia da narrativa, como já destacamos em artigo anterior (2012), leva o espectador a perder as referências no que diz respeito ao estatuto da imagem contemplada. Além da câmera que conduz o desenvolvimento da narrativa fílmica, há a câmera misteriosa do outro e as câmeras da televisão cujas imagens também são exibidas na tela maior. Os vídeos e os desenhos enviados são imagens isoladas que compõem uma outra narrativa, fragmentária, mas que perturba a narrativa coerente dos franceses intelectualizados.

No filme, o jogo de câmeras coloca em evidência a tensão entre visibilidade e clandestinidade: a visibilidade daqueles que impõem seu discurso é utilizada como arma para abalar a estabilidade de suas posições. $O$ intelectual famoso que é visto no programa da TV torna-se objeto de olhar clandestino do descendente de imigrantes não assimilado pela França. Se o outro foi excluído da cultura letrada, se não lhe foi permitido o domínio sofisticado do universo da escrita, as imagens são usadas para criar uma contraposição a esse mundo, trazendo à tona o que fora recalcado pela chamada civilização ocidental. $O$ argelino invisível para os franceses usa a própria invisibilidade para produzir imagens que não deixam o passado colonialista cair no esquecimento - passado este que deixou suas marcas nos comportamentos dos franceses, por mais que se pretenda recalcá-lo, como se vê na cena mencionada em que Georges ofende um negro que involuntariamente quase o atropela com a bicicleta, demonstrando que não aprendeu a conviver com a diferença, não perdeu o sentimento de superioridade.

Os imigrantes pobres, oriundos das antigas colônias, e seus descendentes, como vemos nos filmes mencionados, são vestígios indesejados da violência da colonização, que se procura esquecer. As ex-colônias, se trabalhamos com o sentido moderno de cosmopolitismo, não primam por oferecer ao mundo um número significativo de cidadãos cosmopolitas: nas últimas décadas, entretanto, têm oferecido, aos países centrais, intelectuais diaspóricos, cujas teorias caracterizam-se pelos quadros conceituais híbridos, frutos de um pensamento que se quer desenraizado. Paralelamente, as elites internacionais, cosmopolitas e ecléticas, como destacou Serge Gruzinsky (2001: 41), têm também adotado uma nova retórica, na qual o híbrido vem desbancando o exótico, na esteira de um idioma planetário do consumo que pede empréstimo às culturas do mundo para pôr no mercado novos produtos.

\section{Referências Bibliográficas}

APPADURAI, Arjun. El rechazo de las minorias: ensayo sobre la geografia de la furia. Barcelona: Tusquets, 2007.

BAUMAN, Zygmunt. Globalização: as conseqüências humanas. Rio de Janeiro: Jorge Zahar, 1999.

BECK, Ulrich. La mirada cosmopolita o la guerra es la paz. Barcelona: Paidós, 2005.

BONASSI, Fernando. Passaporte. São Paulo: Cosac \& Naif, 2001.

BORGES, Jorge Luis. "O escritor argentino e a tradição". In: Discussão. São Paulo: Difel, 1986.

FIGUEIREDO. Vera Lúcia Follain de. Narrativas migrantes: literatura, roteiro e cinema. Rio de Janeiro: PUC/7 letras, 2010.

A partilha do espaço urbano e a questão do outro próximo: repercussões no discurso teórico e na ficção cinematográfica. Galaxia, São Paulo, n. 24, dez. 2012. 
FUENTES, Carlos. Tiempo mexicano. México: Joaquín Mortiz, 2ª ed., 1972.

GARCÍA MÁRQUEZ, Gabriel. Crônicas 1961-1984. Obra Jornalística 5. Rio de Janeiro/ São Paulo: Record, 2006.

GOMES, Renato Cordeiro. Cosmopolitismos em tempos midiáticos. Trabalho apresentado ao GT Cultura das Mídias do XXIII Encontro Anual da Compós, na Universidade Federal do Pará, Belém, de 27 a 30 de maio de 2014.

GRUZINSKY, Serge. O pensamento mestiço. São Paulo: Companhia das Letras, 2001.

SANTIAGO, Silviano. O cosmopolitismo do pobre: crítica literária e crítica cultural. Belo Horizonte: UFMG, 2004.

SANTOS, Boaventura de Sousa. Para além do pensamento abissal: das linhas globais a uma ecologia de saberes. Novos estudos - CEBRAP, no.79, São Paulo, nov. 2007.

VELHO, Gilberto. Metrópole, cosmopolitismo e mediação. Revista Horizontes antropológicos, Porto Alegre, vol.16, nำ3, junho 2010.

VILLORO, Juan. Itinerários extraterritoriais. Serrote: Revista de ensaios, artes visuais, ideias e literatura, São Paulo, no 17, julho de 2014.

De Quetzalcóatl a Pepsicóatl. Revista Etcetera: para entender os meios. http://www.etcetera.com.mx. Consulta em 02/10/2014.

WENDEN, Catherine Wihtol de. El fenómeno migratório en el siglo XXI: migrantes, refugiados y relaciones internacionales. México: FCE, 2013. 